\title{
EFFECT OF PRETREATMENT ON A PLATINIZED TIN OXIDE CATALYST USED FOR LOW-TEMPERATURE CO OXIDATION
}

\author{
Jean E. Drawdy, Gar B. Hoflund, Steven D. Gardner and Eva Yngvadottir \\ Department of Chemical Engineering \\ University of Florida \\ Gainesville, Florida \\ David R. Schryer \\ NASA Langley Research Center \\ Hampton, Virginia
}

\begin{abstract}
A commercial platinized tin oxide catalyst used for low-temperature co oxidation has been characterized using ion scattering spectroscopy (ISS), Auger electron spectroscopy (AES) and electron spectroscopy for chemical analysis (ESCA) before and after reduction in 40 Torr of CO for 1 hour at various temperatures from 75 to $175^{\circ} \mathrm{C}$. The reduction results in loss of surface oxygen, formation of metallic tin, conversion of platinum oxides to $\mathrm{Pt}-\mathrm{O}-\mathrm{Sn}$ and $\mathrm{Pt}(\mathrm{OH})_{2}$ and a small amount of metallic Pt which alloys with the tin. These results should be useful in understanding how the pretreatment temperature affects the catalytic activity of platinized tin oxide toward co
oxidation.
\end{abstract}

\section{INTRODUCT ION}

Low-temperature, co-oxidation catalysts are important for long-life, closed-cycle operation of $\mathrm{CO}_{2}$ lasers which are used in remote sensing applications such as weather monitoring from space vehicles. The electrical discharge in $\mathrm{CO}_{2}$ lasers decomposes relatively small amounts of $\mathrm{CO}_{2}$ into $\mathrm{CO}$ and $\mathrm{O}_{2}$. While the power output of the laser decreases slowly with loss of $\mathrm{CO}_{2}$ and buildup of $\mathrm{CO}$, it decreases dramatically with buildup of very low $\mathrm{O}_{2}$ concentrations. A solution to this problem is to recombine the discharge products back into $\mathrm{CO}_{2}$ using a heterogeneous catalyst incorporated in some manner into the laser system. In order to meet volume and weight constraints, it is necessary for the catalyst to have a high activity at low temperatures (

Stark et al. (1) have found that platinized tin oxide with or without a $\mathrm{Pd}$ modifier is an effective low-temperature CO oxidation catalyst. Based on this finding, numerous studies of platinized tin oxide systems relating to co oxidation have been carried out (2). A 2 wt. : platinized tin oxide catalyst is now commercially available from Engelhard Industries. Schryer et al. (3) have studied the catalytic behavior of this material toward CO oxidation and found that the activity of the catalyst depends upon the pretreatment conditions used as shown in figure 1. For the pretreatment and reaction conditions used (see figure 1), the unpretreated catalyst exhibits the lowest long-term activity. A $100^{\circ} \mathrm{C}$ pretreatment in CO greatly enhances the long-term activity, and a further enhancement occurs by carrying out the pretreatment at $125^{\circ} \mathrm{C}$. Utilizing higher pretreatment temperatures up to $225^{\circ} \mathrm{C}$ yields no change in the catalytic activity compared to the $125^{\circ} \mathrm{C}$ pretreatment. In order to understand 
how platinized tin oxide catalysts function in converting $\mathrm{CO}$ and $\mathrm{O}_{2}$ to $\mathrm{CO}_{2}$ at low temperatures, it is necessary to characterize the composition and chemical states of the species present at these surfaces. This has been accomplished in this study using several surface chacterization techniques including ion scattering spectroscopy (ISS), electron spectroscopy for chemical analysis (ESCA) and Auger electron spectroscopy (AES) to examine the surface of the Engelhard catalyst before and after pretreatment in $\mathrm{CO}$ as a function of pretreatment temperature. It is anticipated that these studies will lead to a better understanding of this catalytic process and eventually to the development of improved catalysts for this application.

\section{EXPER IMENTAL}

The Engelhard platinized tin oxide catalyst has an average particle size of $1 \mu \mathrm{m}$ and a BET surface area of $6.9 \mathrm{~m}^{2} / \mathrm{g}$. For the characterization studies the powder was pressed into thin disks about $1 \mathrm{~cm}$ in diameter. These were inserted directly into the ultrahigh vacuum system for pretreatment and characterization. Pretreatment was carried out by moving the sample into a preparation chamber (base pressure of $10^{-7}$ Torr), adjusting the pressure to 40 Torr in $\mathrm{CO}$ and heating the sample at the prescribed temperature for 1 hour. Then the sample was allowed to cool while the preparation chamber was pumped down to $10^{-7}$ Torr before moving the sample into the characterization chamber (base pressure of $10^{-11}$ Torr) for analys is by ISS, ESCA and AES. The samples were heated at $75,100,125$ and $175^{\circ} \mathrm{C}$ in the preparation chamber using a sample heater (4) which did not expose the reducing gas to hot spots which would have dissociated the $C O$. Two different as-prepared samples were analyzed without prereduction, and the results were found to be reproducible. A new sample was prepared and introduced into the analysis chamber for each reduction temperature used.

ISS, ESCA and AES data were taken using a double-pass cylindrical mirror analyzer (CMA) (Perkin-Elmer PHI Model 25-270) as the charged-particle energy analyzer. ISS spectra were collected in the nonretarding mode using a $147^{\circ}$ scattering angle and pulse counting detection (5). A $1-k e V, 100 \mathrm{nA}{ }^{4} \mathrm{He}$ primary ion beam was defocused over a 1-cm-diameter area, and spectra were collected as quickly as possible (typically $90 \mathrm{~s}$ ) to minimize beam damage. AES was performed in the nonretarding mode using a 3-keV, 10- $\mu \mathrm{A}$ primary electron beam with a $0.2-\mathrm{mm}$ spot diameter. ESCA was performed in the retarding mode using $\mathrm{Mg} \mathrm{K \alpha}$ excitation and $50 \mathrm{-eV}$ pass energy for collection of survey spectra and $25 \mathrm{eV}$ for obtaining elemental lineshape information.

\section{RESULTS AND DISCUSSION}

An ESCA survey spectrum taken from the as-received, Engelhard platinized tin oxide catalyst is shown in figure 2. The peaks present of significant size are due only to $O$ and $\mathrm{Sn}$, and no peaks due to $\mathrm{C}$ or other typical contaminants appear. In fact, this spectrum is essentially identical to an ESCA spectrum obtained from a very clean tin oxide surface. It is most interesting that the predominant $\mathrm{Pt}$ $4 \mathrm{f}$ peaks are so small that they cannot be readily discerned in this spectrum. A corresponding Auger spectrum taken from the same surface is shown in figure 3. Again, the predominant features are due to $\mathrm{Sn}$ and $\mathrm{O}$, and this spectrum is similar to one obtained from a clean tin oxide surface. However, a feature due to Pt appears at about $64 \mathrm{eV}$. It can be described as an edge rather than a typically shaped Auger peak. Similar Pt 
features have been observed in a study of the electrochemisorption of Pt on tin oxide (6). This feature is more prominent than the Pt ESCA peaks in figure 1. In agreement with the ESCA data, no contaminant peaks are apparent in this Auger spectrum. As the catalyst is reduced at various temperatures, very small changes are observed in the ESCA and Auger spectra corresponding to figures 1 and 2 but taken from the reduced surfaces. Therefore, these survey spectra are not shown.

ISS is a particularly useful technique for examining catalytic surfaces because it is very highly surface sensitive (outermost one or two atomic layers). ISS spectra taken before (a) and after (b-e) reduction are shown in figure 4. The spectrum shown in (a) consists of peaks due to 0 , Sn, and $\mathrm{Pt}$, and the high inelastic background is characteristic of ISS spectra taken from nonmetallic surfaces. In such a case inelastically scattered ions are not efficiently neutralized since the electron mobility at a nonmetallic surface is low so these ions contribute to the background signal. A previous study by Asbury and Hoflund (7) showed that 0 penetrates beneath the surface during a room-temperature, oxygen exposure of polycrystalline $S n$. This suggests that the fairly large 0 peak in (a) is due to 0 associated with the $\mathrm{Pt}$ and/or perhaps with hydroxyl groups attached to $\mathrm{Sn}$ (8) which may lie above the surface.

The ISS spectra shown in figure 1 (b) to (e) were obtained from samples reduced in 40 Torr of $C O$ for 1 hour at $75,100,125$ and $175^{\circ} \mathrm{C}$ respectively. All four spectra have two characteristics in common. Firstly, the pretreatments have resulted in negligible inelastic backgrounds which is indicative of the formation of surfaces with a metallic nature. Secondly, the 0 peak is no longer discernable after the reductions which is also consistent with the observation that the surfaces appear to be metallic. The reductive pretreatment results in an increase in the Sn-to-Pt ratio, and the extent of this increase is greater at higher reduction temperatures. An increase in the ISS $\mathrm{Sn} / \mathrm{Pt}$ ratio during reduction has been found to be indicative of alloy formation as described in a study of platinized tin oxide model catalysts by Gardner et al. (9). All of the ISS spectra shown in figure 4 were taken using the same instrument settings, but the maximum peak heights vary considerably. Although the variation is not understood, it could be due to changes in ion neutralization probability, surface morphological changes or changes in the concentration of surface hydrogen which have been shown to alter the ISS signal strength $(10,11)$.

Sn 3d ESCA spectra and Sn(MNN) AES spectra taken before and after reduction are shown in figures 5 and 6 respectively. Before pretreatment (airexposed sample) the $\mathrm{Sn} 3 \mathrm{~d}_{5 / 2}$ lineshape and peak position (486.4 eV) indicate that the $\mathrm{Sn}$ is present in the +2 or +4 oxidation states most likely as Sno, $\mathrm{Sn}(\mathrm{OH})_{2}, \mathrm{SnO}_{2}$ or $\mathrm{Sn}(\mathrm{OH})_{4}$ and that metallic $\mathrm{Sn}$ is absent. As discussed by Hoflund et al. (12), it is not possible to distinguish between these species based on the ESCA Sn 3d peaks, but more specific information can be gained about these species using electron energy loss spectroscopy (ELS) $(13,14)$, valence-band ESCA $(8,14)$, electron stimulated desorption (ESD) $(8,15)$ or secondary ion mass spectrometry (SIMS) (16-18). The metallic ESCA Sn $3 d_{5 / 2}$ peak appears at an energy of $484.6 \mathrm{eV}(19)$. When a small amount of metallic Sn and a relatively large amount of tin oxides or hydroxides are present, a slight broadening appears on the low binding energy sides of the oxidic ESCA Sn 3d features. This is the case for the $175^{\circ} \mathrm{C}$-reduced sample as shown in 
figure 5. Samples reduced at lower temperatures also yield this metallic shoulder, and the amount of metallic $\mathrm{Sn}$ produced generally increases as the annealing temperature increases with the most being produced at $175^{\circ} \mathrm{C}$. However, the amounts of metallic $\mathrm{Sn}$ produced at 75 and $100^{\circ} \mathrm{C}$ appear to be similar. Similar observations can be made by considering the AES Sn(MNN) peaks shown in figure 6 . The high kinetic energy oxidic peak lies at $430 \mathrm{eV}$ while the high kinetic energy metallic peak lies at $423 \mathrm{eV}$. The peaks shown in figure $6 a$ are characteristic of oxidic $\mathrm{Sn}$. When metaliic $\mathrm{Sn}$ is present, the height of the splitting between the two primary peaks decreases. This is observed in spectra (b) to (e) taken from the reduced samples. In agreement with the ESCA Sn 3d spectra, the extent of metallic Sn formation is greater at elevated reduction temperatures with the maximum amount of metallic Sn being produced at $175^{\circ} \mathrm{C}$. Further reduction either for prolonged periods or at higher temperatures than used in this study would undoubtedly result in the production of increased amounts of metallic Sn.

The ESCA 0 is peaks are shown in figure 7 . These were taken before (a) and after reduction at (b) $175^{\circ} \mathrm{C}$. The peak shown in (a) exhibits a distinct asymmetry on the high binding energy side due to the presence of hydroxyl groups which are responsible for a shoulder at about $531.8 \mathrm{eV}(8,20)$. It is also possible that the very small shoulder at about $533.0 \mathrm{eV}$ is due to adsorbed water. This assignment is consistent with results obtained in the study of hydrated polycrystalline tin oxide films by Tarlov and Evans (20). Pretreatment at $75^{\circ} \mathrm{C}$ slightly reduces the amounts of adsorbed water and hydroxyl groups present while pretreatment at $100^{\circ} \mathrm{C}$ or above eliminates the adsorbed water and further reduces the concentration of hydroxyl groups. The $175^{\circ} \mathrm{C}$ pretreatment results in the lowest surface hydroxyl group concentration. It is interesting to note that these hydroxyl species are strongly bonded to the surface and require annealing at $600^{\circ} \mathrm{C}$ in vacuum for nearly complete removal $(8,14,21)$.

The 0 content of the near-surface region is decreased by the pretreatment process. The AES and ESCA $0 / S n$ atomic ratios obtained at the various pretreatment temperatures are listed in table I. A decrease in the O/Sn ratio is caused by loss of adsorbed water, a decrease in hydroxyl group concentration, reduction of tin oxides and hydroxides to metallic $\mathrm{Sn}$ and reduction of $\mathrm{SnO}_{2}$ to Sno. However, the relative importance of these factors cannot be completely assessed from the types of data taken in this study. The amount of Pt present on these surfaces is so small that changes in the Pt oxidation state, which are discussed below, would not affect the $\mathrm{O} / \mathrm{Sn}$ atomic ratios presented in table I. The AES and ESCA results in table I are different both with respect to magnitude and trend. The AES data indicate that the near-surface region loses about $20 \%$ of its 0 regardless of the reduction temperature. The ESCA $0 / \mathrm{Sn}$ atomic ratios are considerabiy larger than the AES values and decrease monotonically as the pretreatment increases. Either the ESCA values differ from the AES values due to inaccuracies in the tabulated cross sections or the variation is due to the fact that AES and ESCA probe different volumes of the near-surface region. If the difference were due only to inaccurate cross sections, then the ESCA O/Sn ratios obtained from the reduced samples would not show such a large variation with reduction temperature. Thus, the variation is due to the fact the ESCA probes more deeply than AES, which is consistent with mean-free-path arguments also. The kinetic energies of the ESCA 0 is electrons are $723 \mathrm{eV}$ and the $\mathrm{Sn} 3 \mathrm{~d}$ electrons are about $770 \mathrm{eV}$, while the kinetic energies of the AES 0 electrons are about $510 \mathrm{eV}$ and the Sn electrons are about $430 \mathrm{eV}$. The corresponding average mean free paths ( $\lambda$ ) are about 
$6 \AA$ for ESCA and $4 \AA$ for AES (24). Since most of the ESCA and AES electrons originate within a depth of about $3 \lambda$, ESCA probes about 18 \& beneath the surface while AES probes about $12 \AA$. Then, the data of table I indicate that the near-surface region probed by AES contains less 0 than the region probed by ESCA for the untreated sample and samples reduced from 75 to $175^{\circ} \mathrm{C}$. Reduction at any of the temperatures used causes the AES O/Sn ratio to drop from 1.32 to about 1.06 whereas to ESCA O/Sn ratio decreases monotonically as the reduction temperature increases. The essentially constant AES value probably results from a competing process, i.e., $\mathrm{O}$ leaving the surface as $\mathrm{CO}_{2}$ during the reduction and 0 migrating to the near-surface region from further beneath the surface. This is consistent with the trend of the ESCA data implying that subsurface reduction takes place to a greater extent at higher temperatures. A similar phenomenon has been observed previously for the reduction of a $\mathrm{TiO}_{2}(001)$ surface (25).

The ESCA Pt $4 \mathrm{f}$ peaks obtained from the unpretreated samples are shown in figure $8 \mathrm{a}$, and the peak assignments used in this study are 1 isted in table II. Most of these assignments were taken from a standard reference (19), but the $72.3 \mathrm{eV}$ feature has been assigned as $\mathrm{Pt}-0-\mathrm{Sn}$ in previous studies of platinized tin oxide surfaces $(12,23)$. The spectrum shown in figure 8 a indicates that very little metallic Pt is present and that the Pt species consist mostly of $\mathrm{Pt}-\mathrm{O}-\mathrm{Sn}, \mathrm{Pt}(\mathrm{OH})_{2}$ and $\mathrm{Pt}$ oxides. In fact, a spectrum very similar to this one has been taken from a codeposited platinum/tin oxide film after calcining in air at $725 \mathrm{~K}$ for 1.5 hours (12).

ESCA Pt $4 f$ spectra taken after pretreating at 75 and $100^{\circ} \mathrm{C}$ are shown in figures $8 b$ and c respectively. These two spectra are quite similar in that very little metallic $P t$ is present and the predominant species consist of PtO-Sn and Pt $(\mathrm{OH})_{2}$. The metallic Pt apparently is in the form of small crystallites. A shoulder due to $\mathrm{PtO}_{2}$ may also be present in both spectra, but this shoulder is smaller after the $100^{\circ} \mathrm{C}$ reduction. The relative amounts of Pt-0$\mathrm{Sn}$ and $\mathrm{Pt}(\mathrm{OH})_{2}$ are similar in both spectra. Pretreating at a temperature $25^{\circ} \mathrm{C}$ higher produces a significant change in the Pt species present as shown in figure 8d. The predominant $P t$ species after the $125^{\circ} \mathrm{C}$ reduction are $\mathrm{Pt}(\mathrm{OH})_{2}$ and Pt-O-Sn in approximately equal amounts. Also, a small amount of metallic Pt is present after this treatment, and features due to Pt oxides do not appear.

Reduction at $175^{\circ} \mathrm{C}$ produces a further and more pronounced shift in $\mathrm{Pt}$ chemical state toward $\mathrm{Pt}(\mathrm{OH})_{2}$ as shown in figure $8 \mathrm{e}$. The Pt-O-Sn feature is now a shoulder on the $\mathrm{Pt}(\mathrm{OH})_{2}$ peak, and the amount of metallic Pt present is decreased compared to the lower temperature reductions. The spectrum shown in figure 8 a, taken from the untreated sample, exhibits a prominent feature at $79.8 \mathrm{eV}$. Since the splitting between the $\mathrm{Pt} 4 \mathrm{f}_{7 / 2}$ and $\mathrm{Pt} 4 \mathrm{f}_{5 / 2}$ peaks is about $3.35 \mathrm{eV}$, this feature does not correspond to the $\mathrm{Pt} 4 \mathrm{f}_{5 / 2}$ peak of any of the species 1 isted in table II. The $75^{\circ} \mathrm{C}$ pretreatment reduces the size of this feature, and it does not appear after the 100 or $125^{\circ}$ pretreatment. Therefore, it behaves like an oxidic feature and reappears in figure $8 \mathrm{e}$.

It is interesting to compare the spectral information contained in figure 8 with the kinetic information contained in figure 1. The unpretreated catalyst exhibits a low activity compared to any reduced catalyst. This correlates with the facts that the $P t$ is predominantly oxidic on the unpretreated catalyst and that significant changes in the Pt chemical state occur during 
the reductive treatments used in these studies. As the pretreatment temperature increases, more of the $\mathrm{Pt}$ is converted into $\mathrm{Pt}(\mathrm{OH})_{2}$. This fact suggests that the Pt $(\mathrm{OH})_{2}$ plays an important role in the conversion of $\mathrm{CO}$ and $\mathrm{O}_{2}$ into $\mathrm{CO}_{2}$ at low temperatures as has also been found to be the case for a silicasupported platinized tin oxide catalyst (26) for which the catalytic activity increases by addition of water to the reaction mixture after pretreating the catalyst at $225^{\circ} \mathrm{C}(27)$. The previous characterization study (26) demonstrates that pretreatment of this catalyst at $225^{\circ} \mathrm{C}$ removes most of the Pt hydroxyl species thereby lowering its catalytic activity. This does not occur with the Engelhard catalyst which yields identical catalytic behavior for pretreatments from 125 to $225^{\circ} \mathrm{C}$. The ESCA data are consistent with this fact in that much of the $\mathrm{Pt}$ is present as $\mathrm{Pt}(\mathrm{OH})_{2}$ after the $125^{\circ}$ reduction, and it becomes the predominant $\mathrm{Pt}$ chemical state after the $175^{\circ} \mathrm{C}$ reduction. In this discussion a relationship is being drawn between the long-term catalytic behavior (past the first 500 minutes of operation) and the chemical state of the Pt after the pretreatment but before the reaction is run (time $=0$ on figure 1 ). The initial catalytic behavior is quite complex (3) and changes may occur in the Pt chemical state during this period. Consequently, characterization studies are in progress in which the state of the catalytic surface is being examined as the reaction is run for various periods of time. These studies should lead to an understanding of the chemical changes responsible for the unusual initial catalytic behavior and the long-term decay in catalytic activity.

A small amount of metallic Pt forms during both the 125 and $175^{\circ} \mathrm{C}$ pretreatment, and metallic $S n$ is also present as stated above. Paffett and Windham (28) have deposited layers of $\mathrm{Sn}$ on $\mathrm{Pt}$ (111) and found that alloy formation during annealing at or above $150^{\circ} \mathrm{C}$ is strongly suggested by their data. Also Fryberger* has found that Pd deposited on $\mathrm{SnO}_{2}(110)$ alloys with the $S n$ even at room temperature. It is anticipated that alloy formation occurs in the Engelhard catalyst under the pretreatment conditions used in this study. Since the amount of $P t$ present on this surface is small, most of the metallic $\mathrm{Sn}$ probably is not alloyed while all of the Pt probably is alloyed.

\section{SUMMARY}

A platinized tin oxide catalyst commercially available from Engelhard Industries for low-temperature $\mathrm{CO}$ oxidation has been examined using surface analytical techniques including ISS, AES and ESCA before and after pretreatment by annealing in 40 Torr of $\mathrm{CO}$ for 1 hour at $75,100,125$ and $175^{\circ} \mathrm{C}$, and the results have been correlated with catalytic activity data. The unpretreated sample consists primarily of oxidic $\mathrm{Sn}\left(\mathrm{SnO}_{2}\right.$, $\mathrm{SnO}$ and $\left.\mathrm{Sn}(\mathrm{OH})_{\mathrm{X}}\right)$ with a very small amount of $\mathrm{Pt}$ present as $\mathrm{Pt}-\mathrm{O}-\mathrm{Sn}, \mathrm{Pt}(\mathrm{OH})_{2}$, $\mathrm{PtO}$ and $\mathrm{PtO}_{2}$ species. Reduction results in loss of both $\mathrm{O}$ and $\mathrm{OH}$ from the $\mathrm{Sn}$ and produces metallic $\mathrm{Sn}$. The extent of these processes increases as the pretreatment temperature increases. The chemical state of the Pt changes with pretreatment temperature. At or below $100^{\circ} \mathrm{C}$, the predominant forms are $\mathrm{Pt}-\mathrm{O}-\mathrm{Sn}$ and $\mathrm{Pt}(\mathrm{OH})_{2} \cdot$ As the reduction temperature increases, more $\mathrm{Pt}(\mathrm{OH})_{2}$ forms. This fact suggests that $\mathrm{Pt}(\mathrm{OH})_{2}$ plays an important role in the low-temperature catalytic oxidation of $\mathrm{CO}$. The results demonstrate that the application of surface analytical techniques in studies of real catalysts can provide information which is useful in understanding catalytic behavior.

\footnotetext{
${ }^{*}$ T. Fryberger, personal cormunication
} 


\section{ACKNOWLEDGMENT}

JED, GBH, EY and SDG received financial support for this research under NASA grant NAGI-794. 


\section{REFERENCES}

1. D.S. Stark, A. Crocker and G.J. Steward, J. Phys. E: Sci. Instrum. $16(1983) 158$.

2. Closed-Cycle, Frequency-Stable $\mathrm{CO}_{2}$ Laser Technology, edited by C.E. Batten, J.M. Miller, G.M. Wood, Jr. and D.V. Willetts, NASA Conference Publication 2456, 1987.

3. D.R. Schryer, B.T. Upchurch, J.D. Van Norman, K.G. Brown and J. Schryer, J. Catal. 00(1990)00.

4. G.R. Cora11o, "Chemical and Electronics State Characterization of the Surface Region of Metals Following Chemisorption of Simple Gases," PhD Dissertation, University of Florida, 1987.

5. R.E. Gilbert, D.F. Cox and G.B. Hoflund, Rev. Sci. Instrum. $53(1982) 1281$.

6. H.A. Laitinen, J.R. Waggoner, C.Y. Chan, P. Kirszensztejn, D.A. Asbury and G.B. Hoflund, J. Electrochem. Soc. 133(1986)1568.

7. D.A. Asbury and G.B. Hoflund, J. Vac. Sci. Technol. A 5(1987)1132.

8. G.B. Hoflund, A.L. Grogan, Jr., D.A. Asbury and D.R. Schryer, Thin Solid Films $169(1989) 69$.

9. S.D. Gardner, G.B. Hoflund, M.R. Davidson and D.R. Schryer, J. Catal. $115(1989) 132$.

10. E. Taglauer and W. Heiland, Appl. Phys. 9(1976)261.

11. H.H. Brongersma, M.J. Sparnaay and T.M. Buck, Surface Sci. $71(1978) 657$.

12. G.B. Hoflund, D.A. Asbury and R.E. Gilbert, Thin Solid Films $129(1985) 139$.

13. D.F. Cox and G.B. Hoflund, Surface Sci. 151(1985)202.

14. D.F. Cox, G.B. Hoflund and H.A. Laitinen, Appl. Surface Sci. $20(1984) 30$.

15. G.B. Hoflund, Scanning Electron Microscopy IV(1985)1391.

16. D.F. Cox, G.B. Hoflund and W.H. Hocking, Appl. Surface Sci. $26(1986) 239$.

17. G.B. Hoflund, P.H. Holloway and W.H. Hocking, in Secondary Ion Mass Spectrometry SIMS IV, Proceedings of the Fourth International Conference, Osaka, Japan, edited by A. Benninghoven, J. Okano, R. Shimizu and H.W. Werner, Springer-Verlag, Berlin 36(1984)231.

18. G.B. Hoflund, D.F. Cox, F. Ohuchi, P.H. Holloway and H.A. Laitinen, Appl. Surface Sci. 14(1982-3)281. 
19. C.D. Wagner, W.M. Riggs, L.E. Davis, J.F. Moulder and G.E. Muilenberg (editor), Handbook of X-Ray Photoelectron Spectroscopy, Perkin-Elmer Corporation, Eden Prairie, Minnesota, 1979.

20. M.J. Tarlov and J.F. Evans, Chem. Mater. 0J(1989)00.

21. E.W. Giesekke, H.S. Gutowsky, P. Kirkov and H.A. Laitinen, Inorg. Chem. 6(1967)1294.

22. L.E. Davis, N.C. MacDonald, P.W. Palmberg, G.E. Riach and R.E. Weber, Handbook of Auger Electron Spectroscopy, Perkin-Elmer Corporation, Eden Prairie, Minnesota,1972.

23. S.F. Cox, G.B. Hoflund and H.A. Laitinen, Langmuir 1(1985)269.

24. M.P. Seah and W.A. Dench, Surf. Interface Anal. 1(1979)2.

25. G.B. Hoflund, H.-L. Yin, A.L. Grogan, Jr., D.A. Asbury, H. Yoneyama, 0. Ikeda and H. Tamura, Langmuir 4(1988)346.

26. S.D. Gardner, G.B. Hoflund, D.R. Schryer and B.T. Upchurch, in Proceedings of SPIE - International Society for Optical Engineering; Laser Applications in Meteorology and Earth and Atmospheric Remote Sensing edited by M.M. Sokoloski, published by SPIE, Bellingham, Washington, $1062(1989) 21$.

27. B.T. Upchurch, D.R. Schryer, G.M. Wood and R.V. Hess, in Proceedings of SPIE - International Society for Optical Engineering: Laser Applications in Meteorology and Earth and Atmospheric Remote Sensing, edited by M.M. Sokoloski, published by SPIE, Bellingham, Washington, 1062(1989)287.

28. M.T. Paffett and R.G. Windham, Surface Sci. 208(1989)34. 
TABLE I

O/Sn Atomic Ratios Versus Pretreatment Temperature

$\begin{array}{ccc}\text { Pretreatment } & \text { AES }^{\dagger} & \underline{\text { ESCA }}^{\dagger+} \\ \text { untreated } & 1.32 & 1.56 \\ 75^{\circ} \mathrm{C} & 1.08 & 1.45 \\ 100^{\circ} \mathrm{C} & 1.05 & 1.39 \\ 125^{\circ} \mathrm{C} & 1.04 & 1.33 \\ 175^{\circ} \mathrm{C} & 1.05 & 1.21\end{array}$

TCalculated using methods described in reference 22.

${ }^{\dagger \dagger}$ Calculated using methods described in reference 19.

TABLE II

ESCA Pt $4 f$ Peak Assignments

Species

$\mathrm{Pt}^{\circ}(\mathrm{buIk}){ }^{1}$

$\mathrm{Pt}^{\circ}(\text { crystallite })^{2}$

$P t-0-S n^{2}$

$\mathrm{Pt}(\mathrm{OH})_{2}{ }^{1}$

Pto 1

$\mathrm{PtO}_{2} 1$
Binding Energy (eV)

70.9

$71 \cdot 3$

72.3

72.8

74.2

74.9

1. Assignments taken from reference 19.

2. Assignments taken from references 12 and 23 . 


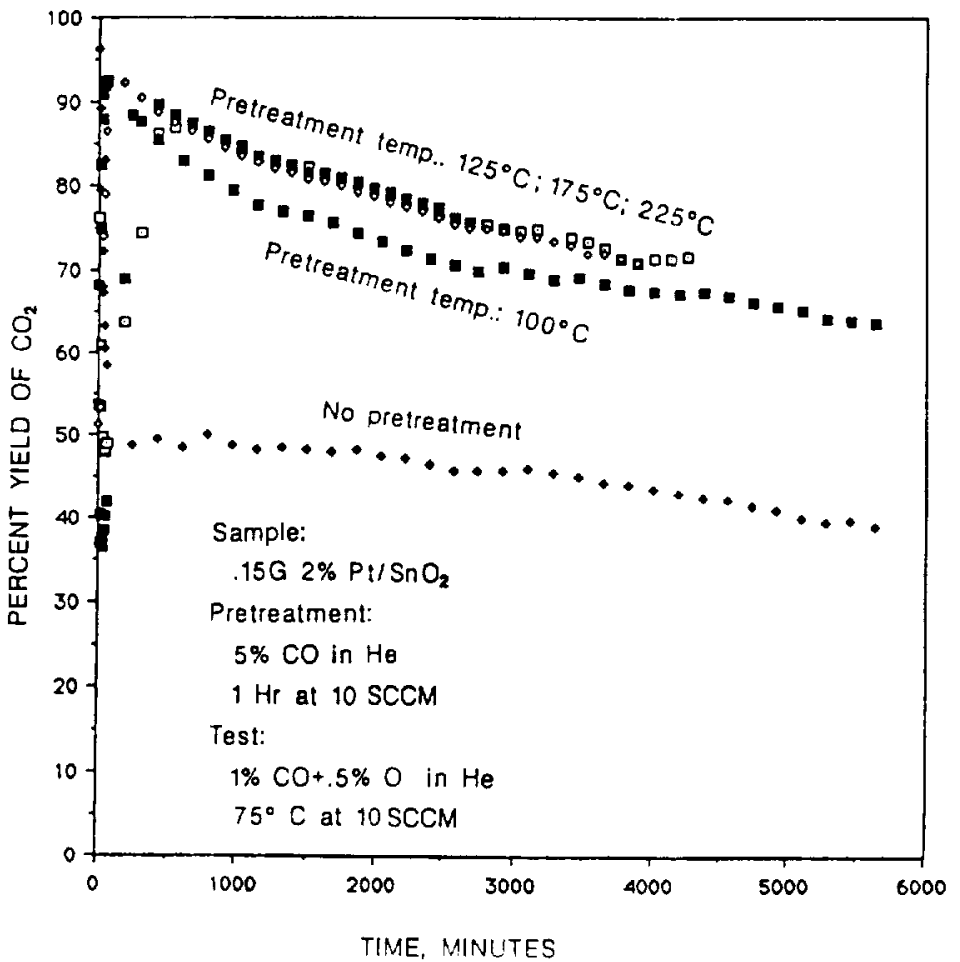

Figure 1. Catalytic activity of the Engelhard platinized tin oxide catalyst for CO oxidation shown as a function of time and pretreatment temperature. The pretreatment and reaction test conditions are given in the figure.

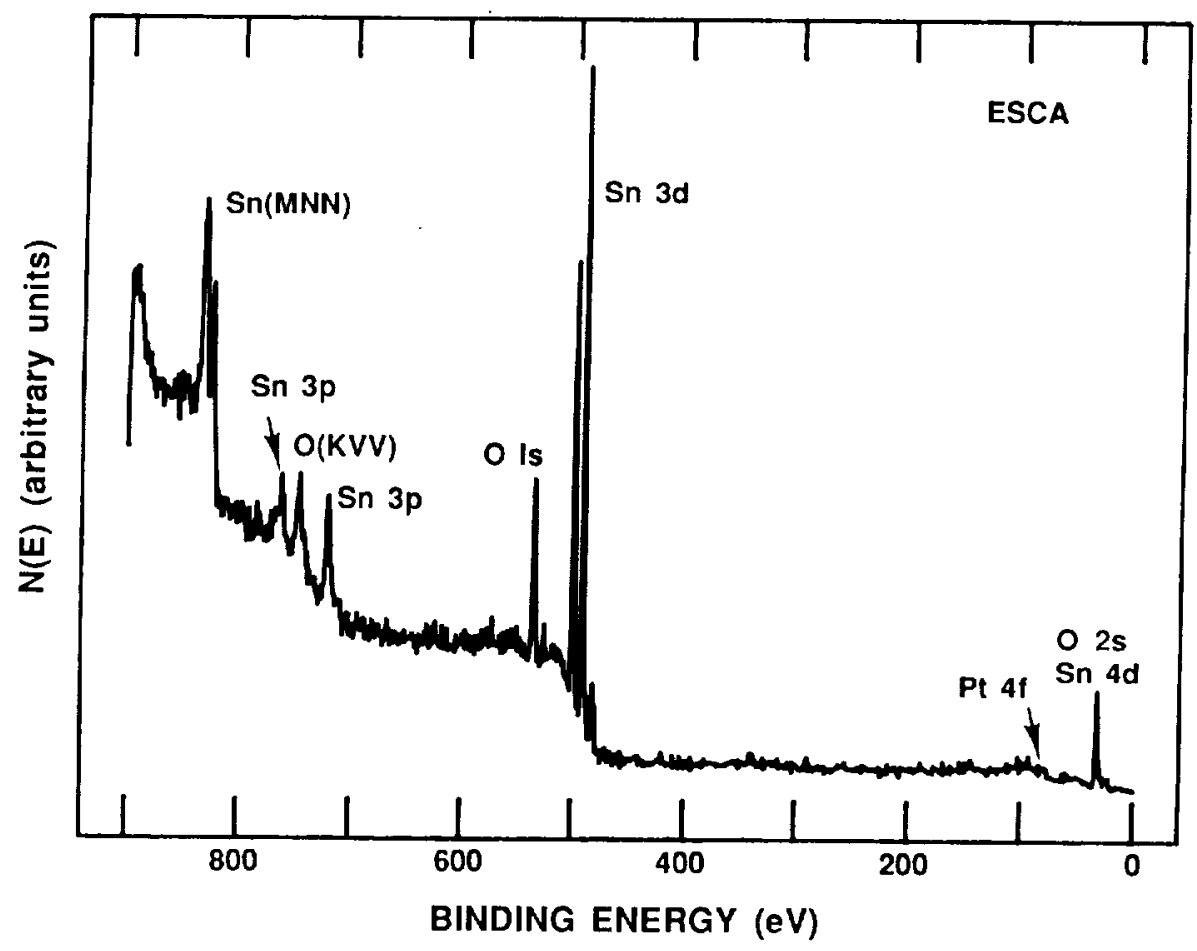

Figure 2. ESCA survey spectrum taken from the as-received Engelhard platinized tin oxide catalyst. 


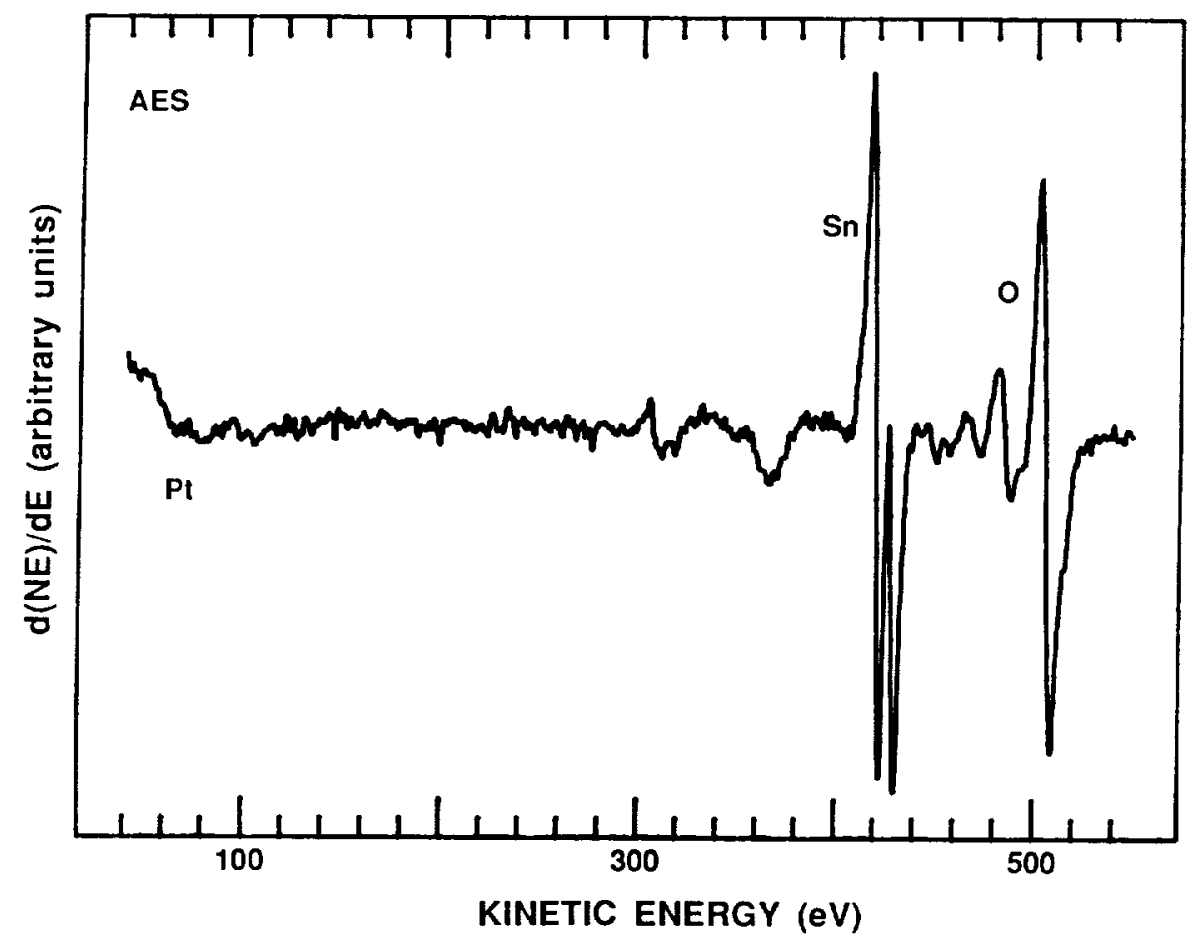

Figure 3. Auger spectrum taken from the same as-received sample as the ESCA spectrum shown in figure 2 .

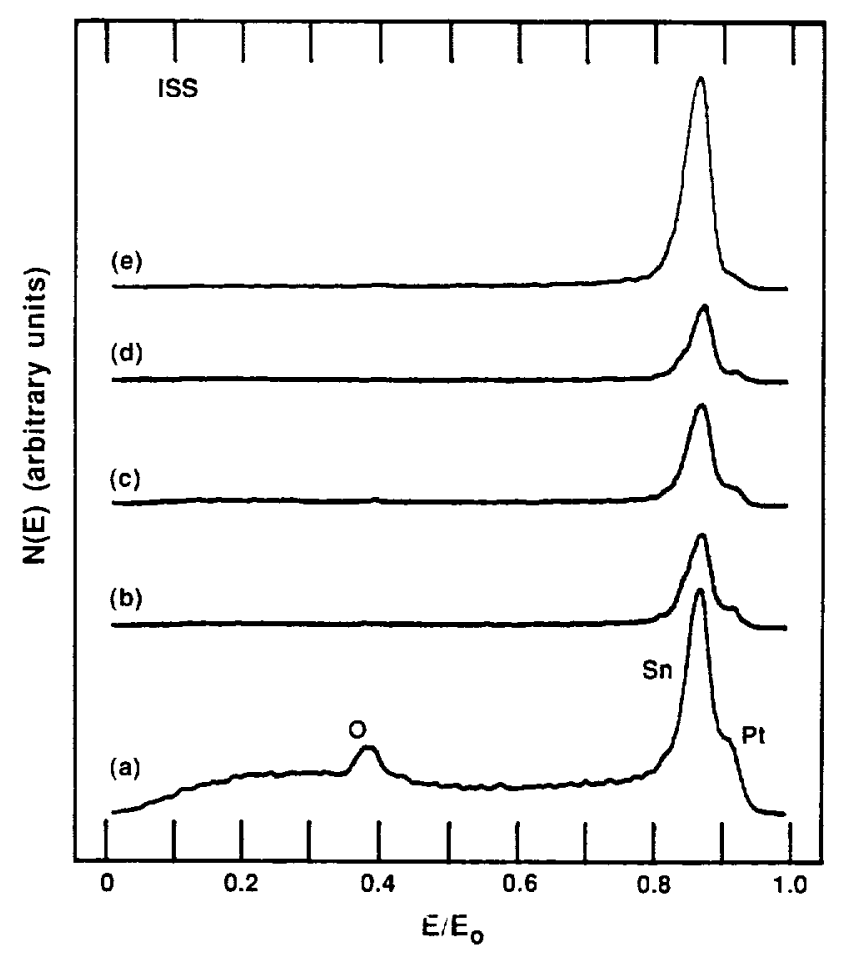

Figure 4. ISS spectra taken from (a) an unpretreated sample and samples reduced at (b) 75 , (c) 100 , (d) 125 and (e) $175^{\circ} \mathrm{C}$ in 40 Torr of $\mathrm{CO}$ for 1 hour. 


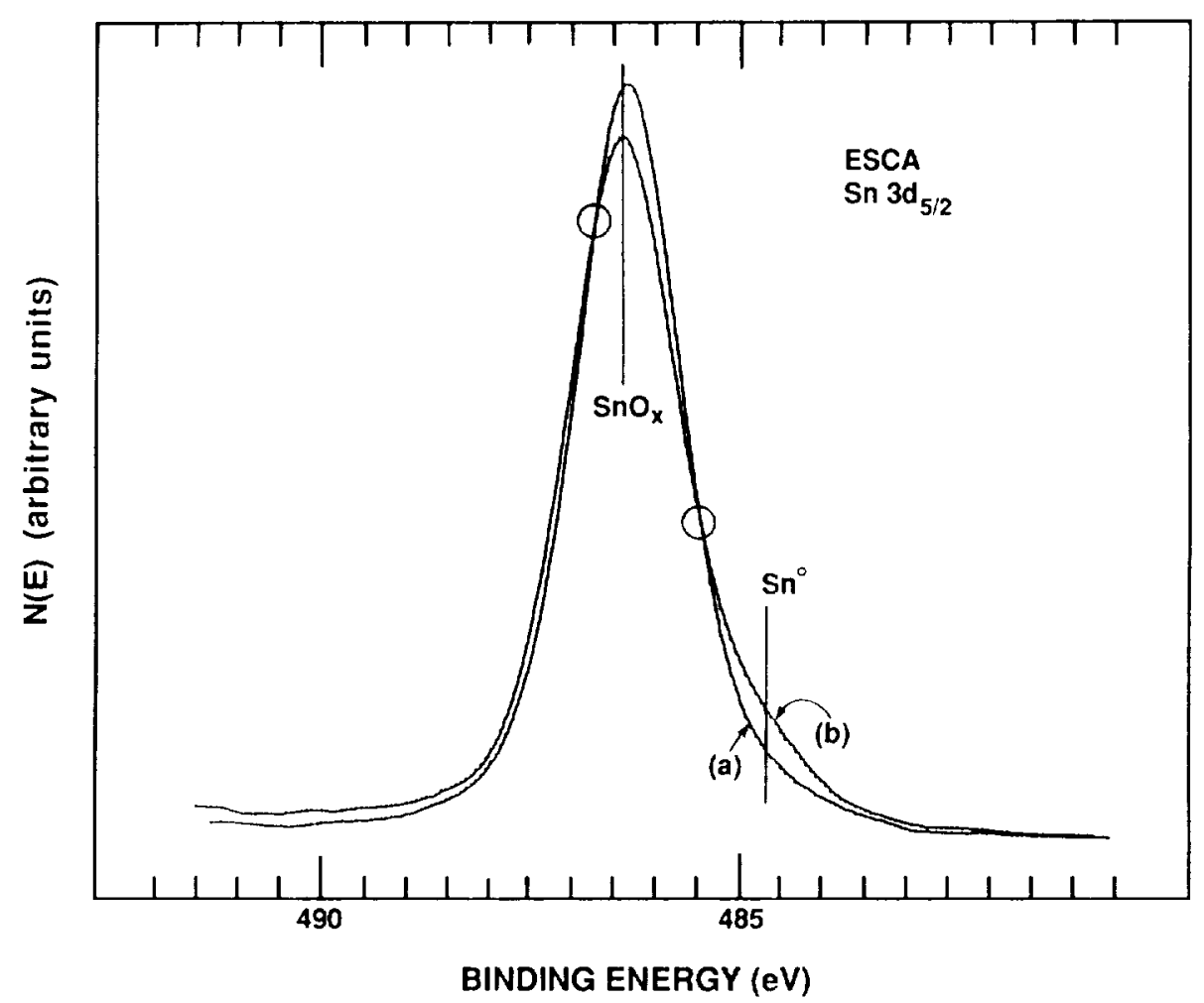

Figure 5. ESCA Sn 3d peaks obtained from (a) an unpretreated sample and (b) a sample reduced at $175^{\circ} \mathrm{C}$ in 40 Torr of CO for 1 hour. The circled regions indicate crossing points.

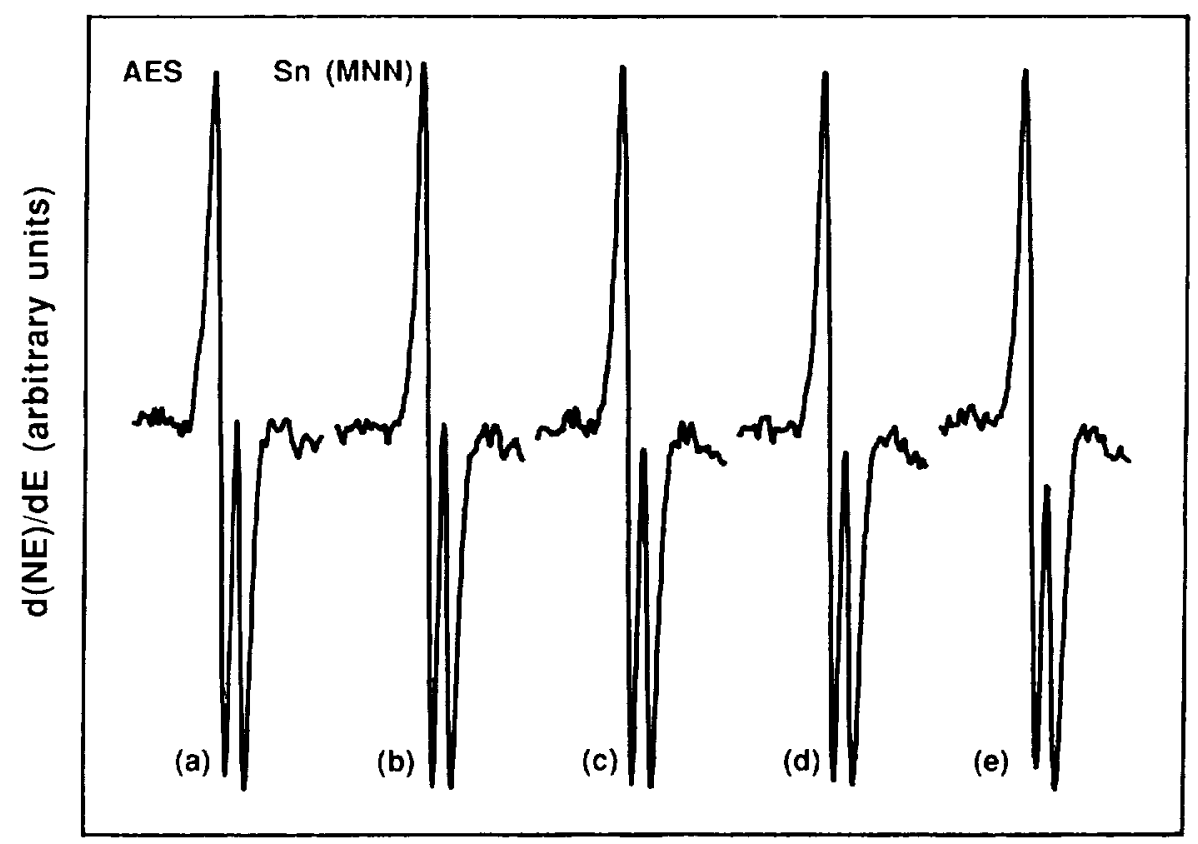

KINETIC ENERGY

Figure 6. AES $S n$ (MNN) peaks obtained from (a) an unpretreated sample and samples reduced at (b) 75, (c) 100, (d) 125 and (e) $175^{\circ} \mathrm{C}$ in 40 Torr of CO for 1 hour. 


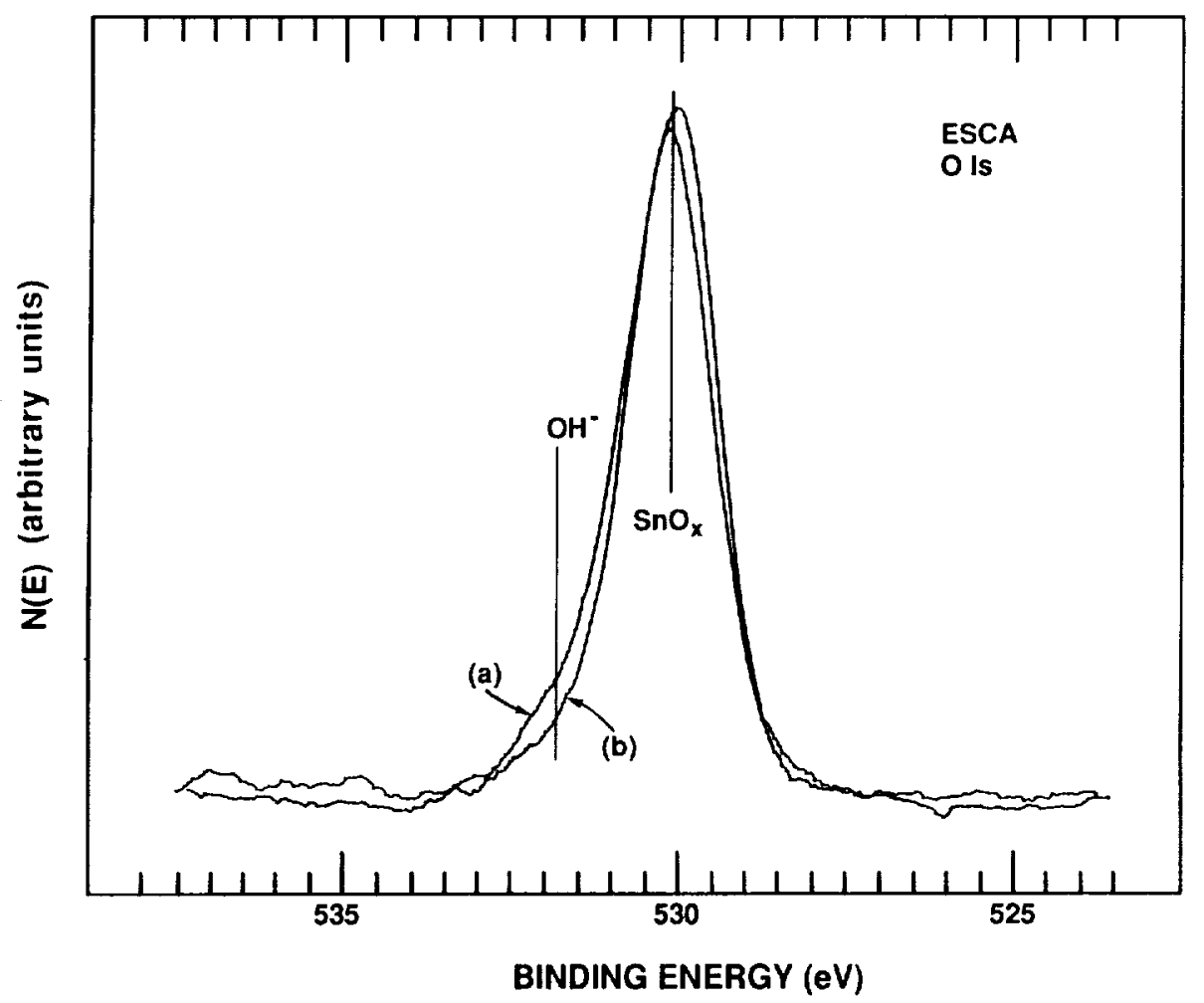

Figure 7. ESCA 0 1s peaks obtained from (a) an unpretreated sample and (b) a sample reduced at $175^{\circ} \mathrm{C}$ in 40 Torr of Co for 1 hour. 


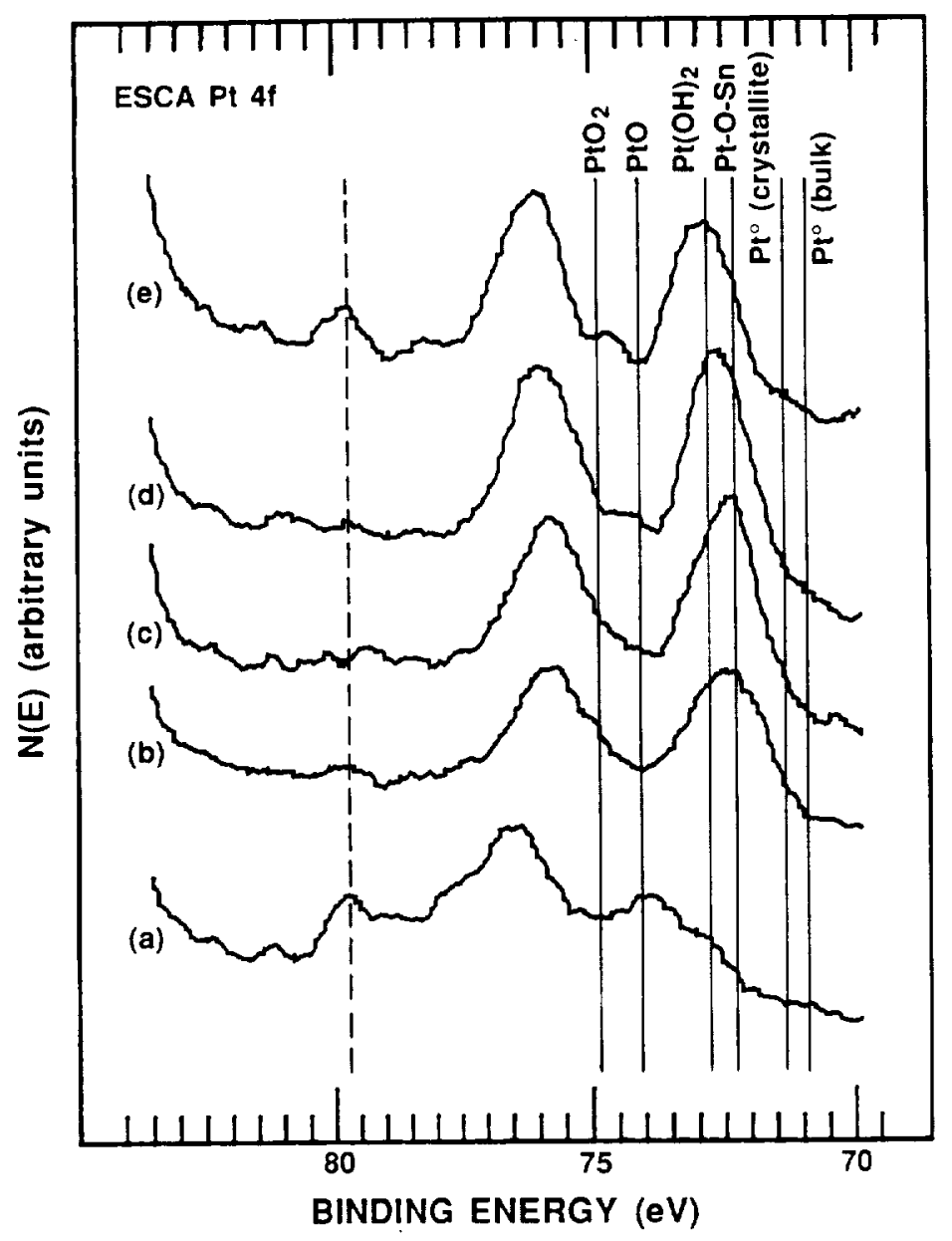

Figure 3. ESCA Pt $4 f$ peaks obtained from (a) an unpretreated sample and samples reduced at (b) 75, (c) 100, (d) 125 and (e) $175^{\circ} \mathrm{C}$ in 40 Torr of co for 1 hour. 
